\title{
Epidemiology and Clinical Features of Peritonsillar Abscess: Is It Related to Seasonal Variations?
}

\author{
Original InvestigatioN \\ Nurullah Seyhun (D, Zeynep Aslı Batur Çalış (D), Merve Ekici (D), Suat Turgut (D) \\ Department of Otorhinolaryngology and Head \& Neck Surgery, Şişli Hamidiye Eftal Training and Research Hospital, İstanbul, Turkey
}

\section{Abstract}

ORCID IDs of the authors: N.S. 0000-0002-6236-7479; Z.A.B.C.. 0000-0003-3897-6650; M.E. 0000-0003-1034-0765; S.T. 0000-0001-9364-2149.

Cite this article as: Seyhun N, Batur Çalıs ZA, Ekici M, Turgut S. Epidemiology and Clinical Features of Peritonsillar Abscess: Is It Related to Seasonal Variations? Turk Arch Otorhinolaryngol 2018; 56(4): 221-5.

\section{Corresponding Author:}

Nurullah Seyhun; seyhun90@hotmail.com

Received Date: 05.03 .2018

Accepted Date: 06.05 .2018

(c) Copyright 2018 by Official Journal of the Turkish Society of Otorhinolaryngology and Head and Neck Surgery Available online at www.turkarchotolaryngol.net

DOI: $10.5152 /$ tao.2018.3362
Objective: Peritonsillar abscess (PTA) is defined as pus accumulation between the tonsillar capsule and constrictor pharyngeal muscle. It can be seen as a complication of acute tonsillitis, but other mechanisms have also been proposed. In this study we aimed to reveal the seasonal variations and epidemiologic features of PTA.

Methods: This is a retrospective, observational study. We reviewed 221 patients, and together with 24 recurrent cases, 245 admissions were reviewed in total. Age, gender, the duration of admission, seasonal and monthly distribution of cases, diabetes and smoking status, white blood cell count, and C-reactive protein (CRP) levels were recorded. Monthly and seasonal incidences of PTA were reviewed to see if there is any association of climate variations and PTA incidence rate. Features associated with the length of hospitalization and recurrence were also analyzed.

Results: A total of 245 PTA cases were admitted to our clinic between June 2014 and June 2017. The highest amount of cases was observed in spring and winter. The $\mathrm{C}$-reactive protein and white blood cell count (WBC) levels were found to be positively correlated with the length of hospitalization. There was no statistically significant correlation with recurrence and smoking, the WBC levels, CRP levels, and length of prior hospitalization. Diabetes status was not found to be associated with length of hospitalization and CRP levels.

Conclusion: The present study reflects the epidemiologic and clinical features of PTA in İstanbul. Our findings showed that seasonal variation was not significant, consistent with previous studies. The highest incidence rate was observed in spring and winter. Length of hospitalization was found to be positively correlated with $\mathrm{C}$-reactive protein and white blood cell count (WBC) levels. Recurrence was not statistically correlated with and smoking, the WBC levels, CRP levels, and length of hospitalization. More studies are recommended to reveal the different epidemiologic factors affecting the incidence of PTA.

Keywords: Peritonsillar abscess, tonsillitis, epidemiology, seasons

\section{Introduction}

Peritonsillar abscess (PTA) is a localized infection defined as pus accumulation between the tonsillar capsule and constrictor pharyngeal muscle. This condition is thought to be a complication of acute tonsillitis and is mainly seen following peritonsillar cellulitis. Another theory is that inflammation of the Weber glands, minor salivary glands located close to the tonsils, may be the causative factor (1). Medical and surgical treatment is needed to relieve the symptoms, and inpatient treatment may be necessary. It is mainly seen in adolescents or young adults, but all age groups can be affected (1). It presents as a sore throat, fever, dysphagia, trismus, and altered voice, and on examination, tonsillar hypertrophy, peritonsillar swelling, and hyperemia can be seen. This condition mainly resolves with simple drainage and medical treatment, but if adequate treatment is not implemented, it can lead to life threatening complications. Airway obstruction, mediastinitis, and hemorrhage due to vascular involvement and septicemia are highly lethal complications of PTA $(2,3)$. In this study, we aimed to reveal the epidemiologic and clinical findings and seasonal variations of 245 PTA cases treated in our clinic between June 2014 and June 2017. 


\section{Methods}

This is a cross-sectional study including 221 patients admitted to our clinic for PTA between June 2014 and June 2017. Twenty-four cases of recurrence were observed, and in total, 245 admissions were reviewed. All the patient data were retrieved from the medical records. Our hospital is a tertiary care center in the middle of Istanbul, which has a population of almost 20 million. Patients were admitted to the clinic for close observation. Proper treatment with antibiotics and analgesics were given. Patients were hydrated intravenously if needed. Before admission, needle aspiration and incision drainage were routinely performed under local anesthesia, and the evidence of pus was used to make the definite diagnosis of PTA. Age, gender, duration of admission, seasonal and monthly distribution of cases, diabetes and smoking status, white blood cell count (WBC), and C-reactive protein (CRP) levels were recorded. Monthly and seasonal incidences of PTA were reviewed to see if there is any association of climate variations and PTA incidence rate. Features associated with the length of hospitalization and recurrence were also analyzed. Patients without purulent discharge following the incision were not included in the study. This study was approved by the Ethical Committee of Şişli Hamidiye Etfal Training and Research Hospital in January 2018. As this is a retrospective study, patient consent was not sought.

Statistical Package for the Social Sciences (SPSS) version 15.0 for Windows programme (SPSS Inc.; Chicago, IL, USA) was used. In subgroup analysis, a chi-square test was used to compare quantitative data. If two different groups were compared for quantitative variables, Mann-

Table 1. Age and gender distribution of patients

\begin{tabular}{l|l|c|c}
\hline \multicolumn{1}{|c|}{} & & $\mathbf{n}$ & $\%$ \\
\hline \multirow{2}{*}{ Gender } & Male & 136 & 61.5 \\
\hline \multirow{2}{*}{ Age } & Female & 85 & 38.5 \\
\hline & $10-18$ yo & 30 & 13.6 \\
\hline & $18-40$ yo & 156 & 70.6 \\
\hline & $40-60$ yo & 29 & 13.1 \\
\hline yo: years old & $>60$ yo & 6 & 2.7 \\
\hline
\end{tabular}

Whitney U-test and Spearman's rank correlation coefficient was used. P-values of 0.05 or less were considered significant.

\section{Results}

A total of 245 PTA cases were admitted to our clinic between June 2014 and June 2017. One hundred and thirty-six patients were male $(61.5 \%)$, and 85 were female (38.5\%). Twenty-four patients were re-admitted for recurrence. The mean age of the patients was $29.9 \pm 6.3$ (range 10-83). The youngest patient was a 10-year-old male, and the oldest patient was an 83-year-old male, although PTA is not common in elderly patients. Patients were divided into four groups according to age. The PTA incidence was significantly higher in the young adult group (18-40 years old) (Table 1). In all age groups, the incidence rate was not significantly different between male and female patients $(\mathrm{p}=0.880)$ (Table 2). The mean length of hospitalization (LH) was $3.4 \pm 1.3$ days (range, 1-10 days). Diabetes mellitus (DM) was present in 12 of the patients (5.5\%). The mean level of CRP was $121.6 \pm 65.1$ (range, $10-329$ ). The mean $\mathrm{WBC}$ was $14.7 \pm 3.7$ (range, 1-30). In patients with DM, the WBC levels were significantly higher $(\mathrm{p}=0.016)$. Recurrence was detected in $24 \mathrm{pa}-$ tients (10.9\%). A smoking status of patients was also recorded, and the mean pack/year smoking was found to be $7.6 \pm 14.1$ (range, 0-90).

Monthly and seasonal incidence rates of PTA were also evaluated. In March and April, the PTA incidences were higher, $10.6 \%$ and $11.8 \%$, respectively. The lowest incidence rate was observed in September (3.3\%). In spring, the PTA incidence was the highest (31.4\%), and in summer and autumn, the incidence of PTA was found to be the lowest, $20.8 \%$ and $20 \%$ respectively (Table 3,4 ).

The LH was positively correlated with the CRP and WBC levels, and these data were statistically significant $(p=0.008$, $\mathrm{p}=0.001$ ), but the smoking status did not correlate with the LH $(\mathrm{p}=0.266)($ Table 5).

Recurrence rate was found to be $10.9 \%$ (24 of 221 patients). When we compared patients with and without recurrent disease, we found that there was no statistically significant correlation with recurrence and smoking, the WBC levels, CRP levels, and length of hospitalization (Table 6).

Table 2. Age subgroups in both genders

\begin{tabular}{|c|c|c|c|c|c|c|c|c|c|c|}
\hline & & \multicolumn{2}{|c|}{$10-18$ yo } & \multicolumn{2}{|c|}{$18-40$ yo } & \multicolumn{2}{|c|}{$40-60$ yo } & \multicolumn{2}{|c|}{$>60$} & $\mathrm{p}$ \\
\hline \multirow[t]{2}{*}{ Gender } & Male & 18 & 60.0 & 98 & 62.8 & 17 & 58.6 & 3 & 50.0 & \multirow[t]{2}{*}{0.880} \\
\hline & Female & 12 & 40.0 & 58 & 37.2 & 12 & 41.4 & 3 & 50.0 & \\
\hline
\end{tabular}


Table 3. Monthly peritonsillar abscess incidences

\begin{tabular}{l|c|c}
\hline \multirow{2}{*}{} & \multicolumn{2}{|c}{ Peritonsillar Abscess Incidence } \\
\cline { 2 - 3 } & $\mathbf{n}$ & $\%$ \\
\hline January & 25 & 10.2 \\
\hline February & 19 & 7.8 \\
\hline March & 26 & 10.6 \\
\hline April & 29 & 11.8 \\
\hline May & 22 & 9.0 \\
\hline June & 17 & 6.9 \\
\hline July & 20 & 8.2 \\
\hline August & 14 & 5.7 \\
\hline September & 8 & 3.3 \\
\hline October & 24 & 9.8 \\
\hline November & 17 & 6.9 \\
\hline December & 24 & 9.8 \\
\hline n: number of patients & & \\
\hline
\end{tabular}

Table 4. Seasonal peritonsillar abscess incidence

\begin{tabular}{l|c|c}
\hline \multirow{2}{*}{} & \multicolumn{2}{|c}{ Peritonsillar Abscess Incidence } \\
\cline { 2 - 3 } Winter & $\mathbf{n}$ & \% \\
\hline Spring & 68 & 27.8 \\
\hline Summer & 77 & 31.4 \\
\hline Autumn & 51 & 20.8 \\
\hline n: number of patients & 49 & 20.0 \\
\hline
\end{tabular}

In diabetic patients, the WBC levels were found to be significantly increased. CRP levels and LH were not sigfinicantly different than patients without DM.

\section{Discussion}

Peritonsillar abscess is defined as pus accumulation between the constrictor pharyngeal muscle and tonsil capsule. It presents as sore throat, difficulty at swallowing, fever, and trismus, and the medical and surgical approach is usually needed (4). We reviewed a total of 221 different patients with PTA that were treated in our tertiary care center, which is in the middle of Istanbul. Istanbul has a population of around 20 million, and climate in Istanbul is similar to other Mediterranean cities. Summer months are generally hot and humid, the average highest temperature is approximately $25^{\circ} \mathrm{C}-27^{\circ} \mathrm{C}$. Winters in Istanbul can be cold, and low temperatures averaging $1^{\circ} \mathrm{C}-4^{\circ} \mathrm{C}$ are seen in general. Spring and autumn are mild, and average temperatures of $15^{\circ} \mathrm{C}-25^{\circ} \mathrm{C}$ are seen (5).
Table 5. Association of patient characteristics and laboratory findings and length of hospitalization

\begin{tabular}{l|c|c|c|c|c|c}
\hline & \multicolumn{2}{|c|}{$\begin{array}{c}\text { Smoking } \\
\text { (Pack/Year) }\end{array}$} & \multicolumn{2}{|c|}{$\begin{array}{c}\text { Length of } \\
\text { Hospitalization }\end{array}$} & \multicolumn{2}{|c}{ CRP } \\
\hline & rho & $\mathbf{p}$ & rho & p & rho & p \\
\hline $\begin{array}{l}\text { Smoking } \\
\text { (Pack/Year) }\end{array}$ & & & & & & \\
\hline $\begin{array}{l}\text { Length of } \\
\text { Hospitalization }\end{array}$ & -0.058 & 0.395 & & & & \\
\hline CRP & -0.046 & 0.494 & 0.385 & $<0.001$ & & \\
\hline WBC & 0.093 & 0.171 & 0.208 & 0.002 & 0.462 & $<0.001$ \\
\hline rho: Spearman's rank correlation coefficient & & & & \\
\hline
\end{tabular}

Table 6. Association of recurrent disease with smoking status, laboratory findings, and the length of prior hospitalization

\begin{tabular}{l|c|c|c|c|c|}
\hline \multirow{2}{*}{} & \multicolumn{5}{|c|}{ Necurrent Disease } \\
\cline { 2 - 6 } & Mean \pm SD & Median & Mean \pm SD & Median & p \\
\hline \begin{tabular}{l|c|c|c|c|} 
Smoking \\
Pack/Year $)$
\end{tabular} & $6.9 \pm 12.6$ & 0 & $13.4 \pm 22.8$ & 2.5 & 0.929 \\
\hline CRP & $121.8 \pm 66.2$ & 106 & $119.6 \pm 56.4$ & 116 & 0.118 \\
\hline WBC & $14.6 \pm 3.8$ & 14 & $15.6 \pm 2.4$ & 15.5 & 0.984 \\
\hline $\begin{array}{l}\text { Length of } \\
\text { Hospitalization }\end{array}$ & $3.40 \pm 1.32$ & 3 & $3.46 \pm 1.53$ & 3 & 0.057 \\
\hline \begin{tabular}{l} 
SD: Standard deviation \\
\hline
\end{tabular} & & & & & \\
\hline
\end{tabular}

Peritonsillar abscess is predominantly reported in males. In our study, male-to-female ration is $1.6: 1$, which is consistent with previous studies $(1,4,6)$ (Table 1$)$. Incidence rates in age groups were consistent with the previous findings in the literature, and PTA is more commonly seen in the adult age group (18-40 years old), whereas recurrent tonsillitis incidence is more common than PTA in children $(1,7)$.

The present study shows that in winter and spring, the PTA incidence is slightly higher. In the literature, there is no consensus on seasonal variation of PTA. In general, it is thought that the PTA incidence is similar in all seasons, but Freire et al. (8) reported that PTA is more common in warmer months, and they found a positive correlation between monthly temperatures and PTA incidence rates. A recent study in Denmark showed that the seasonal variation does not have a statistical significance (9). Winters are mostly cold with occasional snow and rain, and springs are relatively warmer in Istanbul, and we believe that the season does not contribute to the PTA incidence.

In a previous study by Klug et al. (10), smoking was reported to increase the incidence of PTA. However, in our study, we found 
that smoking status is not associated with the risk of recurrence and does not affect the LH.

The recurrence rates of PTA are reported to be between 9\%$22 \%$, and in our study, the recurrence rate was $10.9 \%$ (24 of 221 patients), which is consistent with the literature (11). Smoking status of patients, WBC and CRP levels, and LH were not found to be the predictors of recurrence. In a recent study by Chung et al. (12), recurrent tonsillitis and extraperitonsillar spread on a computed tomography scan were found to be the main risk factors for recurrence. In our study, we did not see any factors associated with recurrence. The recurrence rate is relatively low in our study, which can be because our study is a retrospective one, and as Istanbul is a metropolis, there are many hospitals in a small area, and there may be some patients presented to other hospitals for recurrence of PTA.

Diabetes mellitus (DM) was present in 12 of the patients (5.5\%). In diabetic patients, the WBC levels were found to be significantly increased. The CRP levels and LH were not found to be different than patients without DM. DM is considered to be an immunocompromised state, and deep neck infections are more severe and higher complication rates are seen in DM patients (12). In our study, the number of patients with DM was limited, and this might be the reason for the lack of association with a more severe disease status. It is reported in several studies that DM is not a risk factor for PTA and is not associated with recurrence of PTA $(12,13)$.

The mean LH was 3.4 \pm 1.3 days (range, 1-10 days). Smoking status did not affect the LH and CRP levels. WBC levels were found to be positively correlated with LH. In a study by Liu et al. (14), risk factors for LH were assessed. The authors reported that smoking was not associated with LH, which was similar to our findings, and older ages, positive band form WBC, lower hemoglobin levels, and having a medical history of DM were independent predictors of longer LH. In our study, due to a limited number of patients with DM, we did not find any relationship between DM and LH.

\section{Conclusion}

The present study reflects the epidemiologic and clinical features of PTA in İstanbul. Our findings showed that seasonal variation was not significant, which was consistent with previous studies. The highest incidence rate was observed in spring, when the weather is relatively warm in Istanbul. It may indicate that the PTA incidence is not affected by the temperature. We can also conclude that acute tonsillitis, which peaks during winter and fall when the temperature is low, may not have to precede PTA. We recommend that more studies should be conducted to reveal the epidemiologic factors affecting the incidence of PTA.
Ethics Committee Approval: Ethics committee approval was received for this study from the Ethics Committee of Şişli Hamidiye Şişli Hamidiye Eftal Training and Research Hospital (1854/09.01.018).

Informed Consent: Informed consent was not received due to the retrospective nature of the study.

Peer-review: Externally peer-reviewed.

Author Contributions: Concept - N.S., Z.A.B.Ç., M.E., S.T.; Design - N.S., Z.A.B.Ç., M.E., S.T.; Supervision - N.S., Z.A.B.Ç., M.E., S.T.; Resource - Z.A.B.Ç., M.E., S.T.; Materials - N.S., M.E., S.T.; Data Collection and/or Processing - S.T., M.E., Z.A.B.Ç.; Analysis and/or Interpretation - N.S., M.E.; Literature Search - Z.A.B.Ç., M.E.; Writing - N.S., Z.A.B.Ç.; Critical Reviews - N.S., Z.A.B.Ç., S.T., M.E.

Conflict of Interest: The authors have no conflicts of interest to declare.

Financial Disclosure: The authors declared that this study has received no financial support

\section{References}

1. Mazur E, Czerwinska E, Korona Glowniak I, Grochowalska A, Koziol-Montewka M. Epidemiology, clinical history and microbiology of peritonsillar abscess. Eur J ClinMicrobiolInfectDis 2015;34: 549-54. [CrossRef]

2. Baldassari CM, Howell R, Amorn M, Budacki R, Choi S, Pena M. Complications in pediatric deep neck space abscesses. Otolaryngol HeadNeck Surg 2011;144: 592-5. [CrossRef]

3. Byard RW.Tonsillitis andsudden childhood death. J Forensic Leg Med 2008;15: 516-18. [CrossRef]

4. Ong YK, Goh YH, Lee YL. Peritonsillar infections: local experience. Singapore Med J 45: 105-9.

5. Resmi İstatistikler (İl ve İlçelerimize Ait İstatistiki Veriler)" [Official Statistics (Statistical Data of Provinces and Districts) - Istanbul] (in Turkish). Turkish State Meteorological Service. Retrieved 10 August 2015. Available from: URL: https://mgm. gov.tr/veridegerlendirme/il-ve-ilceler-istatistik. aspx? $\mathrm{m}=\mathrm{IS}$ TANBUL

6. Marom T, Cinamon U, Itskoviz D, Roth Y. Changing trends of peritonsillar abscess. Am J Otolaryngol 2010; 31: 162-7. [CrossRef]

7. Matsuda A, Tanaka H, Kanaya T, Kamata K, Hasegawa M.Peritonsillar abscess: a study of 724 cases in Japan. EarNoseThroat J 2002; 81: 384-9.

8. Freire GSM, DosSantos JHZ, Rolón PA, Pinheiro GB, Sampaio ALL. Peritonsillar abscess: epidemiology and relationship with climate variations. J LaryngolOtol 2017; 131: 627-30. [CrossRef]

9. Klug TE. Incidence and microbiology of peritonsillar abscess: the influence of season, age, and gender. Eur J Clin Microbiol Infect Dis 2014; 33: 1163-7. [CrossRef]

10. Klug TE, Rusan M, Clemmensen KK, Fuursted K, Ovesen T.Smoking promotes peritonsillar abscess. Eur Arch Otorhinolaryngol 2013; 270: 3163-7. [CrossRef]

11. Powell J, Wilson JA. An evidence-based review of peritonsillar abscess. Clin Otolaryngol2012; 37: 136-45 . [CrossRef]

12. Chung JH, Lee YC, Shin SY, Eun YG. Risk factors for recurrence of peritonsillar abscess. J Laryngol Otol 2014; 128:1084-8. [CrossRef] 
13. Albertz N, Nazar G.Peritonsillar abscess: Treatment with immediate tonsillectomy - 10 years of experience. Acta Otolaryngol 2012; 132:1102-7. [CrossRef]
14. Liu YH, Su HH, Tsai YW, Hou YY, Chang KP, Chi CC, et al. Initial factors influencing duration of hospital stay in adult patients with peritonsillar abscess. Clin Exp Otorhinolaryngol 2017; 10: 115-20. [CrossRef] 